\title{
Economical Speed for Optimizing the Travel Time and Energy Consumption in Train Scheduling using a Fuzzy Multi-Objective Model
}

\author{
Ahmad Reza Jafarian-Moghaddam ${ }^{1}$ (D)
}

Received: 10 August 2020/Revised: 31 March 2021/Accepted: 12 May 2021/Published online: 24 June 2021

(C) The Author(s) 2021

\begin{abstract}
Speed is one of the most influential variables in both energy consumption and train scheduling problems. Increasing speed guarantees punctuality, thereby improving railroad capacity and railway stakeholders' satisfaction and revenues. However, a rise in speed leads to more energy consumption, costs, and thus, more pollutant emissions. Therefore, determining an economic speed, which requires a trade-off between the user's expectations and the capabilities of the railway system in providing tractive forces to overcome the running resistance due to rail route and moving conditions, is a critical challenge in railway studies. This paper proposes a new fuzzy multiobjective model, which, by integrating micro and macro levels and determining the economical speed for trains in block sections, can optimize train travel time and energy consumption. Implementing the proposed model in a real case with different scenarios for train scheduling reveals that this model can enhance the total travel time by $19 \%$ without changing the energy consumption ratio. The proposed model has little need for input from experts' opinions to determine the rates and parameters.
\end{abstract}

Keywords Transportation - Scheduling - Economical speed · Fuzzy multi-objective train scheduling model · Energy consumption

Ahmad Reza Jafarian-Moghaddam

ar.jafarian@trn.ui.ac.ir

1 Faculty of Civil Engineering and Transportation, University of Isfahan, 81746-73441 Isfahan, Iran

Communicated by Lixing Yang.

\section{Introduction}

Green rail transport provides the possibility of mass transportation of goods and passengers with high safety and less energy consumption. Accordingly, in most countries facing numerous traffic and environmental problems, rail transport has been widely utilized in urban and suburban environments [1]. Exploiting the benefits of rail transport and providing a safe and efficient form of transport require accurate train scheduling that specifies the arrival and departure time at various stations with minimal conflicts, travel time, and energy consumption [2]. Train speed plays a significant role in the train scheduling problem because it determines the possibility of punctuality, efficient use of the existing infrastructure capacity, and the degree of railway stakeholders' satisfaction [1]. An increase in speed leads to a spike in energy consumption. At higher speeds, resistance against the train movement increases in addition to the need for tractive power. The conditions of the rail route dictate how much tractive force is required to overcome the running resistance [3]. Hence, train speed is also affected by route conditions. Since train operations use $>$ $80 \%$ of the total energy required for railway systems [4], optimal train scheduling will have a huge impact on reducing the energy consumption of railways. For a comprehensive review, refer to Fernández et al. [5].

Accordingly, the role of train speed in energy consumption and railway stakeholders' satisfaction indicates the importance of economical speed determination in the train scheduling problem. The economical speed is an optimal average speed resulting from the conditions of the rail route and rolling stocks that minimizes costs by optimizing energy consumption and increases revenues by reducing travel time. Albrecht et al. [6] showed that it is possible to determine the economical train speed that 
minimizes energy consumption. Besides, in automatic train operation (ATO), which involves the use of driverless train operation (DTO) [7], determining the economical speed, controlling speed, and generating an optimal speed profile are some of the important functions controlled by the system.

Noteworthy, different studies formulate the train scheduling problems at a macroscopic level. However, integrating the macroscopic and microscopic details such as blocks is essential to achieve an accurate and practical timetable [8]. Therefore, we need a trade-off between travel time reduction and energy consumption optimization achieved by increasing and decreasing speed, respectively, in rail route blocks. Accordingly, this paper proposes a new micro-macro non-interactive fuzzy multi-objective model under a green target that optimizes the trains' energy consumption using the economical speed in the block sections due to the relationships between tractive force and resistance during train movement. Moreover, the model minimizes the travel times to meet the punctuality needs and improve the satisfaction of railway customers. Notably, train travel time is the sum of stop time at stations and running time between stations. The next section explains in more detail the gap in railway studies and the research contributions of the proposed model.

\section{Literature Review}

Train scheduling models adjust the arrival and departure time of trains at stations to minimize travel time and prevent train collisions. Scheepmaker et al. [9], Yin et al. [1], and Albrecht et al. [6] had comprehensive review of the train scheduling model. Train scheduling mainly targets travel time, energy consumption, and the satisfaction of passengers and owners of goods. In such models, the railway as a service provider and stakeholders as the service receiver may have conflicting objectives. Therefore, the train scheduling models are sometimes de facto multi-opposite/objective models. For example, increasing the speed of trains, which will reduce passengers' travel time and lead to passenger satisfaction, will raise energy consumption and railway costs, leading to railway operator dissatisfaction. However, in some studies, single-objective models have been considered [10]. Train scheduling problems are non-deterministic polynomial-time (NP)-hard problems, and by raising the number of objectives, the complexity of models increases. This is why some studies have solved algorithms for such problems [11, 12]. These algorithms include heuristic and meta-heuristic algorithms [13-15], branch-and-bound methods [16], column generation [17], constraint generation [18], and stochastic and fuzzy approaches [19-21].
As the processing speed of computer systems has been enhanced, multi-objective train scheduling models and optimization algorithms have received more attention in recent years. $\mathrm{Li}$ et al. [22] formulated train scheduling to improve the quality of service and the efficiency of train operations. Chow and Pavlides [23] and Pavlides and Chow [24] modeled the quality of rail services, such as passenger comfort and travel time, and reduced service costs in rail operations. These models were implemented using the optimization methods in Southeast England.

Today, global warming due to the release of pollutants and the provision of energy-efficient solutions has engaged decision-makers (DMs) and politicians. The International Union of Railways (UIC) planned to reduce emissions in the rail industry by $30 \%$ in 2020 and by $50 \%$ in 2030 compared to 1990 [25] and to integrate the railway with nature by 2050 [26].

Scheepmaker et al. [9] have comprehensively studied energy optimization models in train scheduling. Higgins et al. [27] have proposed a single-objective train scheduling model for reducing travel time and fuel consumption. Using a new bi-objective model, Yang et al. [16] and Ghoseiri et al. [28] have considered the reduction of fuel consumption for ensuring railway satisfaction and reducing the travel time of passengers to guarantee their well-being. Ghoseiri et al. [28] proposed a model that also considered the station platforms' limitations. Yang et al. [16] adopted a fuzzy approach, and Ghoseiri et al. [28] utilized the distance-based method and the $\varepsilon$-constraint method to solve the proposed models. Li et al. [29] decreased carbon emission by reducing energy consumption due to resistance during train movement and by decreasing the travel time of the passengers. They implemented the proposed multi-objective model using fuzzy mathematical programming in the Chinese railway. Parbo et al. [30] proved that the arrival and departure time of trains at stations have a significant role in planning the passengers' live and goods owners and reducing their stress. Sanchis and Zuriaga [31] proposed an optimal speed profile using efficient driving techniques to save energy and improve passenger comfort. They demonstrated that their models reduce net energy consumption by $19 \%$. Li and Zhang [32] increased the market share of railway freight by $39.27 \%$ and reduced carbon emissions by $37.09 \%$ using new integrated models of operation planning and pricing. The model by Huang et al. [33] is a non-cyclic multi-objective model in an urban system designed to save fuel consumption and improve service quality. Cyclic models optimize train scheduling operations for a group of trains, and then this timing is repeated by other groups [34]. In these models, the number of trains does not affect the cost of the model. In non-cyclic models, however, the cost of implementing the model is proportional to the number of trains. Hence, researchers 
have highly regarded non-cyclic models for complex planning in train scheduling problems.

Through investigation, it is found that most researches were focused on macro-level train scheduling. However, Bešinović et al. [8] showed that combining macro and micro levels in the train scheduling problems can improve the railroads' capacity by providing a feasible, stable, and robust timetable. The integrated micro-macro model of Schlechte et al. [35] led to faster planning of train movements and a reality-based timetable provision. Hence, we also present a hybrid model of micro and macro levels. Table 1 compares the reviewed train scheduling models with the proposed model based on different perspectives to illustrate the gaps in the literature. The last row of this table presents the features of the proposed model and its superiority over the other models.

\section{Research Contributions}

A review of the literature shows that most of the models presented in previous studies do not consider the satisfaction of railway and railway customers simultaneously. Besides, given the effect of determining speed in guaranteeing mutual satisfaction in rail transport, its modeling and estimation are vital. Therefore, the proposed model is a multi-objective non-cyclic model optimizing energy consumption by taking into account running resistance and the required tractive force and by determining the economical train speed. The contributions of this study to the state of the art are summed as follows:

- Developing a new multi-objective non-cyclic train scheduling model applicable to railroad's single-line and double-line

- Introducing a green integrated micro-macro train scheduling model

Table 1 A comparison of studies and the proposed model's features

\begin{tabular}{|c|c|c|c|c|c|c|}
\hline \multirow[t]{3}{*}{ Studies } & \multicolumn{6}{|c|}{ Desired features in train scheduling } \\
\hline & \multicolumn{2}{|l|}{ Objectives } & \multicolumn{4}{|c|}{ Constraints and variables } \\
\hline & $\begin{array}{l}\text { Energy } \\
\text { consumed }\end{array}$ & $\begin{array}{l}\text { Travel } \\
\text { time }\end{array}$ & $\begin{array}{l}\text { Tractive } \\
\text { force }\end{array}$ & $\begin{array}{l}\text { Resistance } \\
\text { force }\end{array}$ & $\begin{array}{l}\text { Rail route } \\
\text { conditions }\end{array}$ & $\begin{array}{l}\text { Economical/changeable } \\
\text { speed }\end{array}$ \\
\hline Li and Zhang [32] & $\checkmark$ & $\checkmark$ & $\checkmark$ & $\checkmark$ & $\times$ & $x$ \\
\hline Zhang et al. [15] & $\checkmark$ & $\checkmark$ & $\checkmark$ & $\checkmark$ & $x$ & $\times$ \\
\hline Chow and Pavlides [23] & $\times$ & $\checkmark$ & $x$ & $x$ & $x$ & $\times$ \\
\hline Pavlides and Chow [24] & $x$ & $\checkmark$ & $x$ & $x$ & $x$ & $x$ \\
\hline Huang et al. [33] & $\checkmark$ & $\checkmark$ & $\checkmark$ & $\boldsymbol{V}$ & $x$ & $\times$ \\
\hline Qi et al. [34] & $\checkmark$ & $\checkmark$ & $x$ & $x$ & $x$ & $\times$ \\
\hline $\begin{array}{l}\text { Sanchis and Zuriaga } \\
\text { [31] }\end{array}$ & $\checkmark$ & $\checkmark$ & $\checkmark$ & $\checkmark$ & $x$ & $\times$ \\
\hline Su et al. [36] & $\boldsymbol{V}$ & $\checkmark$ & $\checkmark$ & $\checkmark$ & $x$ & $x$ \\
\hline Li et al. [29] & $\checkmark$ & $\checkmark$ & $\checkmark$ & $\checkmark$ & $x$ & $\times$ \\
\hline Li et al. [22] & $\checkmark$ & $\checkmark$ & $\times$ & $x$ & $x$ & $\times$ \\
\hline Yang et al. [16] & $\checkmark$ & $\checkmark$ & $\times$ & $x$ & $x$ & $\times$ \\
\hline Kroon et al. [37] & $x$ & $\checkmark$ & $x$ & $x$ & $x$ & $x$ \\
\hline Liebchen [10] & $x$ & $\checkmark$ & $x$ & $x$ & $x$ & $x$ \\
\hline Caprara et al. [38] & $x$ & $\checkmark$ & $x$ & $x$ & $x$ & $x$ \\
\hline Zhou and Zhong [39] & $x$ & $\checkmark$ & $x$ & $x$ & $x$ & $\times$ \\
\hline Ghoseiri et al. [28] & $\checkmark$ & $\checkmark$ & $x$ & $x$ & $x$ & $x$ \\
\hline Kroon and Peeters [40] & $x$ & $\checkmark$ & $x$ & $x$ & $x$ & $x$ \\
\hline $\begin{array}{l}\text { Liu and Golovitcher } \\
\text { [41] }\end{array}$ & $\checkmark$ & $\checkmark$ & $x$ & $x$ & $x$ & $x$ \\
\hline Peeters [42] & $x$ & $\checkmark$ & $x$ & $x$ & $x$ & $x$ \\
\hline Higgins et al. [27] & $\checkmark$ & $\checkmark$ & $\times$ & $x$ & $x$ & $\times$ \\
\hline Bešinović et al. [8] & $x$ & $\checkmark$ & $x$ & $x$ & $\checkmark$ & $x$ \\
\hline Schlechte et al. [35] & $\times$ & $\checkmark$ & $\times$ & $\times$ & $\checkmark$ & $x$ \\
\hline Proposed model & $\checkmark$ & $\checkmark$ & $\checkmark$ & $\checkmark$ & $\checkmark$ & $\checkmark$ \\
\hline
\end{tabular}


- Taking the fixed-block system into account when scheduling trains, which can be effective in determining the optimal speed profile for ATO

- Considering the impacts of running resistance and tractive force on trains' movement process

- Determining the economical speed for reducing travel time and energy consumption to enhance stakeholder satisfaction

- Formulating energy consumption from a new perspective with minimum need for setting cost rates and parameters

\section{The Proposed Model}

In train operation management models, the train is considered as a single-point or as a multi-point mass [1]. In single-point train models, the train's components, including wagons and locomotives, are considered as a single mass. This model is a simple well-known modeling technique providing excellent results [6]. Heavy-haul train modeling with a large number of locomotives and wagons uses multi-point train models where a large tractive force is required to overcome the running resistance [43]. This modeling of the train makes the problem more complicated and time-consuming. Since the proposed model is intended to be implemented in railways around the world that have both conventional and light trains, it formulates the train as a single-point mass, and thus speed is assumed to be the same throughout the length of the train.

Figure 1 illustrates a railroad with four points as stations and three blocks. The station is a yard where all rail operations take place [44]. A block is a section of a railroad that only one train is granted to cross at a time [45]. Since the blocks have a significant effect on the rail route capacity, the railways try to improve the line capacity by dividing the length of the blocks and extending the number of blocks between stations. However, the number and length of block sections are affected by the railway infrastructure, tractive force, and the train's ability in braking and acceleration [46]. Although the model does not intend to set the number and length of blocks, these characteristics of blocks as input parameters of the proposed model can affect the accuracy of the results. The model assumes that the beginning and endpoints of each block are stations (Fig. 1). In other words, the points on a rail route will include real stations and hypothetical stations (points between real stations). Consequently, it is possible to issue a permit or prohibit the stopping, crossing, and overtaking of trains at any point (to make this more explicit, refer to the explanation of Eq. 20). Thereby, the proposed model integrates the macro level of the railway with micro-level phenomena. Macro level covers running time, and the arrival and departure time at real stations. Micro level involves running time and the economical speed in blocks, and the arrival and departure time at hypothetical stations or points. This study shows each block section in an interval between these points. For example, the interval $(s, s+1)$ represents a block section between stations or points $s$ and $s+1$. Therefore, we can formulate the proposed micro-macro model for railroads with different lengths and numbers of blocks to provide a more realistic timetable for trains. Additionally, with the hypothetical numbering of the stations, a train moving from station $s$ to station $s+3$ is an outbound train, and a train moving in the opposite direction is an inbound train (Fig. 1).

Note that this paper aims to reduce energy consumption by providing an optimal schedule for trains based on the conditions of the railway rolling stocks and rail routes. For this purpose, the model minimizes the travel time of trains according to the time available and the conditions of their stop at the station. For example, some trains do not need to stop at some stations; however, due to some prudence for trains crossing and overtaking and to prevent the trains from colliding with each other, they are forced to stop at the station. The model attempts to reduce the stopping time of the train at the station by minimizing these conflicts and to realize punctuality by proposing the optimal speed in different block sections. Table 2 lists the sets, parameters, and variables used in the model.

\subsection{Objective Functions}

The proposed model pursues two main objectives: (1) reducing train travel time and (2) decreasing energy consumption. Equation 1 expresses the objective function of the trains' travel time. As mentioned earlier, train travel time includes stopping time at stations and running time.
Fig. 1 The direction of outbound and inbound trains and the relationship between block sections and stations

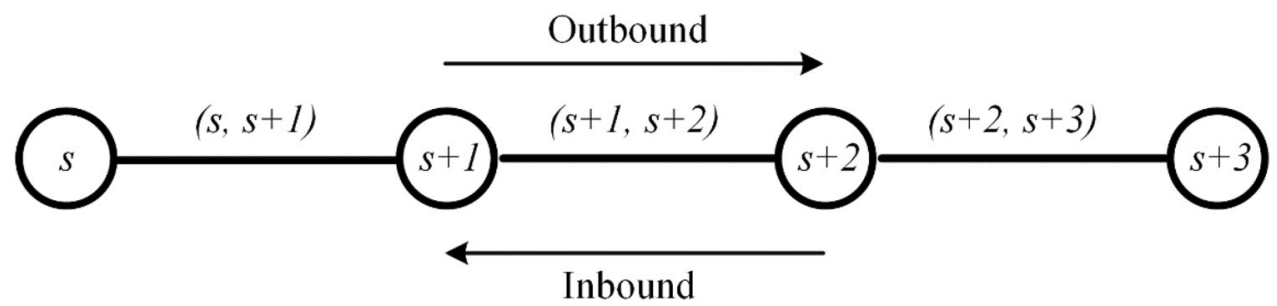


Table 2 Sets, parameters, and variables of the proposed model

\begin{tabular}{|c|c|c|}
\hline Type & Symbols & Description \\
\hline \multirow[t]{3}{*}{ Sets } & $S$ & Set of real and hypothetical stations $\left(S=\left\{1,2, \ldots, S_{n}\right\}\right)$ \\
\hline & $K$ & Trains' set $\left(K=\left\{1,2, \ldots, k, \ldots, K_{n}\right\}\right)$ \\
\hline & $C$ & $\begin{array}{l}\text { Set of train's components including freight and passenger wagons and locomotives } \\
\qquad\left(C=\left\{1,2, \ldots, C_{n}\right\}\right)\end{array}$ \\
\hline \multirow[t]{3}{*}{ Indices } & $s, O, D$ & $\begin{array}{l}\text { Indices for the stations: } O \text { is index for train's origin station, and } D \text { is index for train's } \\
\text { destination station, } s \text { is the index representing stations. }(s, O, D \in S)\end{array}$ \\
\hline & $i, j$ & $\begin{array}{l}\text { Indexes indicating the trains }(i, j \in K) \text { : Outbound trains are numbered from } 1 \text { to } k \text {, and } \\
\text { inbound trains from } k+1 \text { to } K n\end{array}$ \\
\hline & $c$ & Index for train's components $(c \in C)$ \\
\hline \multirow[t]{6}{*}{ Decision variables } & $x_{i s}^{a}$ & Arrival time of train $i$ at station $s$ \\
\hline & $x_{i s}^{d}$ & Departure time of train $i$ from station $s$ \\
\hline & $x_{i O}^{d}$ & Departure time of train $i$ from origin station $O$ \\
\hline & $x_{i D}^{a}$ & Arrival time of train $i$ to destination station $D$ \\
\hline & $v_{i(s, s+1)}$ & Economical speed of train $i$ in block section $(s, s+1)$ \\
\hline & $\begin{array}{l}A_{i j(s, s+1)}, B_{i j(s, s+1)} \\
\quad C_{i j(s, s+1)}\end{array}$ & Binary variables for consecutive trains $i$ and $j$ in block section $(s, s+1)$ \\
\hline \multirow{2}{*}{$\begin{array}{l}\text { Auxiliary decision } \\
\text { variables }\end{array}$} & $T_{i(s, s+1)}^{f}$ & Tractive force of train $i$ in block section $(s, s+1)$ \\
\hline & $R_{i(s, s+1)}$ & Running resistance to the movement of the train $i$ in block section $(s, s+1)$ \\
\hline \multirow[t]{18}{*}{ Parameters } & $S_{n}$ & Number of stations \\
\hline & $K_{n}$ & Number of trains \\
\hline & $C_{n}$ & Number of train's components \\
\hline & $k$ & Number of outbound trains \\
\hline & $v_{i}^{c}$ & Continuous speed of train $i(\mathrm{~km} / \mathrm{h})$ \\
\hline & $v_{i}^{\max }$ & Maximum speed of train $i(\mathrm{~km} / \mathrm{h})$ \\
\hline & $y_{i O}^{d}$ & Earliest allowable departure time of train $i$ from origin station $O$ \\
\hline & $y_{i D}^{a}$ & Latest scheduled arrival time of train $i$ to destination station $D$ \\
\hline & $h_{(s, s+1)}$ & Headway or release time of block section $(s, s+1)$ \\
\hline & $s t_{i s}$ & Scheduled stopping time for train $i$ in station $s$ \\
\hline & $P o_{i}$ & Power of train $i$ (hp: horsepower) \\
\hline & $\rho_{i}$ & Productivity rate of train $i$ \\
\hline & $m_{i c}$ & Mass of a component of train $i$ (tons) \\
\hline & $m_{i}^{t}$ & Total mass of train $i$ (tons) \\
\hline & $n_{i c}$ & Total number of axles of the component $c$ for train $i$ \\
\hline & $\alpha_{(s, s+1)}$ & Angle of ruling grade in block section $(s, s+1)$ \\
\hline & $l_{(s, s+1)}$ & Length of block section $(s, s+1)$ \\
\hline & $N$ & A large positive value \\
\hline
\end{tabular}

The model tries to reduce train stops at stations as much as possible. Conceivably, trains may be forced to stop at the station due to some scheduling and headway requirements [47], but stopping more is considered unpleasant, and consequently, we are trying to reduce this time. Train stops are obtained from the time difference between the departure time and the expected arrival time of the train at the station. However, trains need to stop and wait at certain stations (scheduled stopping time). Therefore, the scheduled stopping time should be deducted from the stops. Note that if train $i$ is not required to stop at station $s$, then $s t_{i s}=0$. The train travel time is calculated from the difference between the departure time at the previous station and the arrival time at the current station. The proposed model attempts to minimize this time difference. The first part of Eq. 1 is the stopping time of trains at the stations, and the second and third parts take into account the running time of the trains. 
Min

$$
\begin{aligned}
& \mathrm{DT}=\sum_{s \in S} \sum_{i \in K}\left(x_{i s}^{d}-x_{i s}^{a}-s t_{i s}\right) \\
& +\sum_{s \in S}\left(\sum_{i \in K, i \leq k}\left(x_{i s+1}^{a}-x_{i s}^{d}\right)+\sum_{i \in K, i>k}\left(x_{i s}^{a}-x_{i s+1}^{d}\right)\right)
\end{aligned}
$$

By mathematical relations, Eq. 1 can be summed up as Eq. 2:

Min $\quad \mathrm{DT}=\sum_{i \in K}\left(x_{i D}^{a}-x_{i O}^{d}\right)-\sum_{s \in S} \sum_{i \in K} s t_{i s}$

Minimizing the travel time of each train from the origin to the destination station is necessary for decreasing the trains' running time and stops. In Eq. 2, since $s t_{i s}$ is a constant value, deleting it from the objective function will not affect the results of the model. Therefore, we represent objective function 2 as objective function 3 .

Min $\quad \mathrm{DT}=\sum_{i \in K}\left(x_{i D}^{a}-x_{i O}^{d}\right), \quad$ for $O, D \in S$

The travel time of a train will be proportional to the speed of the train throughout various block sections. Consequently, objective function 3 reduces the travel time of the trains along the origin-destination stations by increasing the speed of the trains, thereby intelligently controlling the train stops.

Another objective of the proposed model is to optimize the energy consumption of trains. Train speed plays a significant role in determining energy consumption because a tractive force is needed to overcome the running resistance and achieve a certain speed. The tractive force is inversely proportional to speed, while speed and resistance are positively correlated. Assuming that the head locomotives used in the rail network are diesel-electric locomotives-one of the most frequently used locomotives in the railways worldwide- the tractive force of train $i$ in interval $(s, s+1)$ is obtained by Eq. 4 [48]. Note that, in the proposed model, locomotives can be considered differently; this does not change the description and structure of the proposed model, and the model is the same for all locomotives.

$T_{i(s, s+1)}^{f}=\frac{270 P o_{i} \rho_{i}}{v_{i(s, s+1)}} \quad(k g f)$,

for $i \in K$, and $s \in S, s \neq D$

where $k g f$ or the kilogram-force is a metric unit of force.

Running resistance $(R)$ is divided into two groups of permanent resistance and temporary resistance. Permanent resistance $\left(R^{c}\right)$ is the resistance that exists continuously along the train movement. Air, bearings, and wheel/rail resistance constitute the permanent resistance. Temporary resistance $\left(R^{t}\right)$ exists only in some segments of the rail route, and it will not exist after the passage of the train from those segments. Wind, tunnel, curve, and grade resistance are the most important types of this resistance. Therefore, resistance against the movement of train $i$ in block section $(s, s+1)$ is calculated using Eq. 5 .

$R_{i(s, s+1)}=R_{i(s, s+1)}^{c}+R_{i(s, s+1)}^{t}$,

for $i \in K$, and $s \in S, s \neq D$

The equation provided by the American Railways Engineering Association (AREA), called Davis resistance [49], is used to calculate the permanent resistance. Equation 6 shows the Davis resistance for train $i[50,51]$.

$$
\begin{aligned}
& R_{i(s, s+1)}^{c}=\sum_{c \in C}\left(\left(A+\frac{n_{i c} \cdot B}{m_{i c}}\right)+C \cdot v_{i(s, s+1)}+\left(\frac{D \cdot a}{m_{i c} \cdot n_{i c}}\right)\left(v_{i(s, s+1)}\right)^{2}\right)\left(\frac{k g f}{t}\right), \\
& \quad \text { for } i \in K, \text { and } s \in S, s \neq D
\end{aligned}
$$

where $k g f / t$ is the kilogram-force per ton, and $A, B, C, D$, and $a$ are coefficients whose values are given in Table 3 . Davis' formula from the left to the right consists of three parts: the first, second, and third parts are related to wheel/ rail, bearing, and air resistance, respectively.

Temporary resistance in railways is calculated empirically or using conventional mathematical relationships. For example, according to Fig. 2, grade resistance is obtained from Eq. 7.

$R_{g}=m_{i}^{t} g \sin \alpha$

In railways, $\alpha$ is very small and is given in a proportion of 1000 units $(\%)$; therefore, $(\sin \alpha) \approx \alpha$. As a result, Eq. 8 will calculate the grade resistance.

Table 3 Davis' resistance coefficients

\begin{tabular}{lrllll}
\hline Component & \multicolumn{6}{l}{ Davis' coefficients } \\
\cline { 2 - 6 } & \multicolumn{1}{c}{$a$} & \multicolumn{1}{l}{$A$} & \multicolumn{1}{l}{$B$} & \multicolumn{1}{l}{$C$} & \multicolumn{1}{l}{$D$} \\
\hline Locomotive & 12.3 & 0.65 & 13.2 & 0.00931 & 0.00453 \\
Freight wagon & 8.6 & 0.65 & 13.2 & 0.01395 & 0.000944 \\
Passenger wagon & 11.4 & 0.65 & 13.2 & 0.00931 & 0.000642 \\
\hline
\end{tabular}

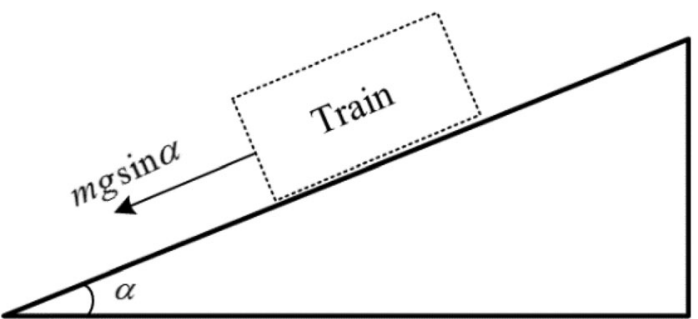

Fig. 2 Calculation of grade resistance 
$R_{g}=m_{i}^{t} \alpha \quad(k g f)$

This paper considers the ruling grade resistance because most of the world's railways take into account the maximum temporary resistance, and in some railways, the determination of fixed coefficients is not specified [1]. The ruling grade, which is the steepest climb on a block section or between two stations, limits the length and weight of the train that can be hauled over the rail route [51]. As a result, the grade resistance is easy to calculate, and it creates the highest resistance against the train movement. According to the description given, Eq. 9 calculates the running resistance against the movement of train $i$ in block section $(s, s+1)$.

$R_{i(s, s+1)}=m_{i}^{t}\left[\sum_{c \in C}\left(\left(A+\frac{n_{i c} \cdot B}{m_{i c}}\right)+C \cdot v_{i(s, s+1)}+\left(\frac{D \cdot a}{m_{i c} \cdot n_{i c}}\right)\left(v_{i(s, s+1)}\right)^{2}\right)+\alpha_{(s, s+1)}\right]$

$(k g f)$, for $i \in K$, and $s \in S, s \neq D$

Figure 3 shows the relationships between $T_{i(s, s+1)}^{f}$ and $R_{i(s, s+1)}$ at various speeds. Note that Eq. 4 calculates the maximum tractive force supplied by the locomotive [52]. In other words, not all the $T_{i(s, s+1)}^{f}$ is needed to move the train, and a force equivalent to $R_{i(s, s+1)}$ will be sufficient to move because the locomotive needs to overcome $R_{i(s, s+1)}$ for moving [3]. We call the force required to move $T_{i(s, s+1)}^{m}$. Accordingly, the relationship between these different forces will be $T_{i(s, s+1)}^{f}>T_{i(s, s+1)}^{m} \geq R_{i(s, s+1)}$. Hence, various studies try to reduce $T_{i(s, s+1)}^{m}$ and indirectly $R_{i(s, s+1)}$ to decrease train energy consumption $[1,15]$. Therefore, since calculating $T_{i(s, s+1)}^{m}$ is very complicated and expensive, by creating a greater difference between the $T_{i(s, s+1)}^{f}$ and $R_{i(s, s+1)}$ forces, we can directly reduce the $R_{i(s, s+1)}$,

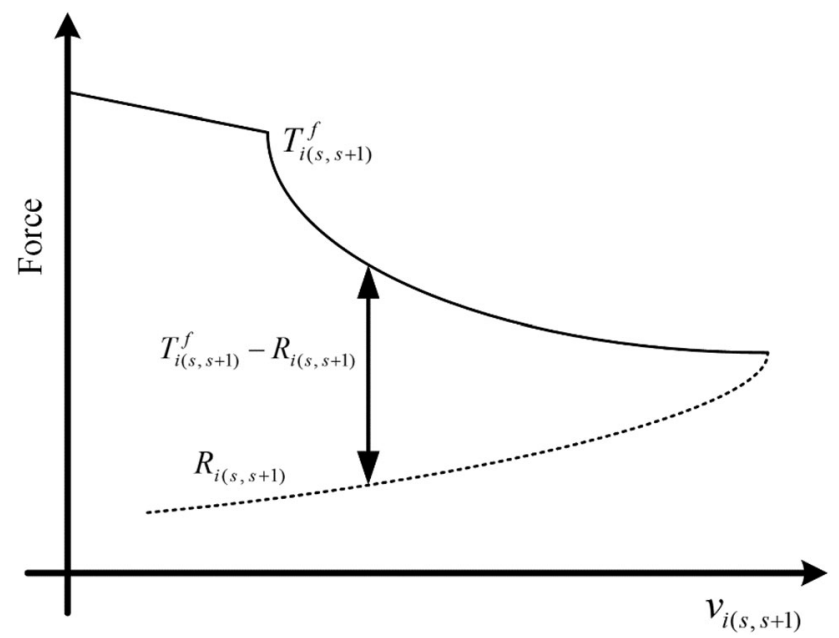

Fig. 3 Tractive force and resistance at various train speeds [53] thus, energy consumption and the force required to move. By this idea, the model considers the simultaneous effects of $T_{i(s, s+1)}^{f}$ and $R_{i(s, s+1)}$ on energy consumption, which is an essential topic that has received little attention in the past. Moreover, Albrecht et al. [6] state that it is possible to achieve a speed at which energy consumption is optimized. In light of the above, since the tractive force $\left(T_{i(s, s+1)}^{f}\right)$ and the resistance $\left(R_{i(s, s+1)}\right)$ are functions of speed in the proposed model, we use the difference between the forces to achieve a speed, named economical speed, that optimizes energy consumption (Fig. 3). This principle is the foundation of the objective function of the proposed model.

According to our principle, the difference between Eqs. 4 and 9 obtains the energy consumption objective function of the proposed model (Eq. 10). The proposed model tries to maximize this difference.

$\operatorname{Max} \quad \mathrm{EC}=\sum_{\substack{s \in S \\ s \neq D}} \sum_{i \in K}\left(T_{i(s, s+1)}^{f}-R_{i(s, s+1)}\right)$

As mentioned earlier, the value of Eq. 10 should be a positive value $\left(T_{i(s, s+1)}^{f}>R_{i(s, s+1)}\right)$ so that the train can travel at the desired speed and complete the run. Objective function 10 tries to reduce energy consumption by decreasing train speed (Fig. 3). Nevertheless, speed reduction will lengthen the train's travel time and lead to complaints from passengers and goods owners. Therefore, objective function 3 increases the trains' speed for ensuring the satisfaction of the stakeholders. As a result, the proposed model has two opposing objectives.

\subsection{Constraints}

The constraints of the proposed model are divided into two groups. The first group includes those that prevent the collision of trains in one direction or opposite directions and ensure the safe movement of trains. The second group comprises the constraints that control the timing and speed of the trains. Therefore, the constraints of the second group control the amount of energy consumption because energy consumption has a positive relationship with travel time and speed. Table 2 presents the variables and parameters used in this analysis.

\subsubsection{Constraints of the safe movement of trains}

According to Jafarian-Moghaddam and Yaghini [54], the proposed model defines the headway in interval $(s, s+1)$ $\left(h_{(s, s+1)}\right)$ as the time interval required for safe entry of the next train to the block section. This new headway definition can reduce the number of model constraints [54]. Different modes of trains' entry to the block can include 
inbound-inbound, outbound-outbound, inbound-outbound, or outbound-inbound. In the inbound-inbound mode (Fig. 4), the constraints to avoid collisions will be as follows [54]:

$$
\begin{aligned}
& N \cdot A_{i j(s, s+1)}+x_{i s+1}^{d} \geq x_{j s}^{a}+h_{(s, s+1)} \\
& N \cdot\left(1-A_{i j(s, s+1)}\right)+x_{j s+1}^{d} \geq x_{i s}^{a}+h_{(s, s+1)}
\end{aligned}
$$$$
\text { for } s \in S \text {, and } i, j>k \in K
$$

in which $A_{i j(s, s+1)}=0$, if $j$ is first passing through block section $(s, s+1)$; otherwise, $A_{i j(s, s+1)}=1$.

If two consecutive trains enter the block in the outbound-outbound mode (Fig. 5), constraint 12 avoids train collisions, where $C_{i j(s, s+1)}=0$ if the $j$ is first passing through the block; otherwise, $C_{i j(s, s+1)}=1$ [54].

$$
\begin{aligned}
& N \cdot C_{i j(s, s+1)}+x_{i s}^{d} \geq x_{j s+1}^{a}+h_{(s, s+1)} \\
& N \cdot\left(1-C_{i j(s, s+1)}\right)+x_{j s}^{d} \geq x_{i s+1}^{a}+h_{(s, s+1)}
\end{aligned}
$$

for $s \in S$, and $i, j \leq k \in K$

Constraint 13 prevents train collisions in inbound-outbound or outbound-inbound train modes (Fig. 6). In these constraints, $B_{i j(s, s+1)}=0$ if the outbound train $j$ is first passing through the block; otherwise, $B_{i j(s, s+1)}=1$ [54]. It should be noted that constraint 13 will be eliminated from the model if there are separate routes for passing trains. In subway lines and urban railways observed in this sample of rail routes, suburban rail networks commonly use single

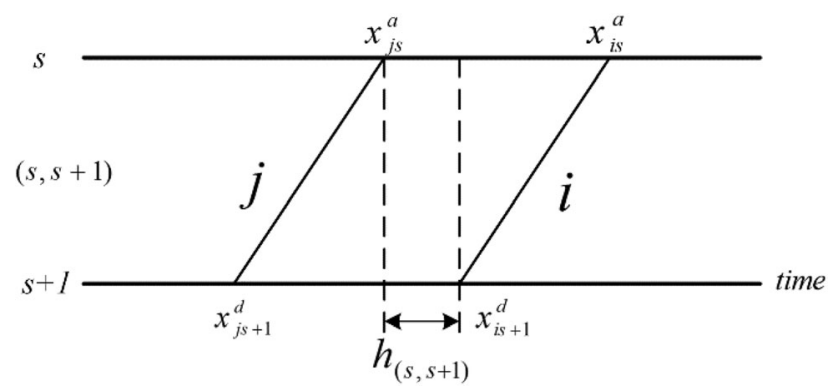

Fig. 4 Inbound-inbound trains' graph in block section $(s, s+1)$

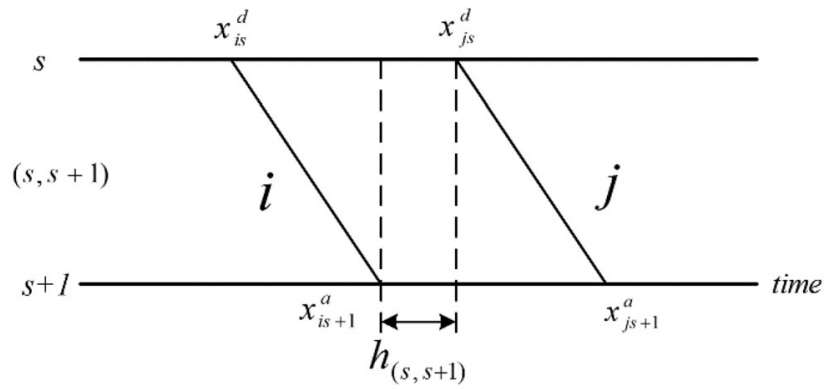

Fig. 5 Outbound-outbound trains' graph in block section $(s, s+1)$

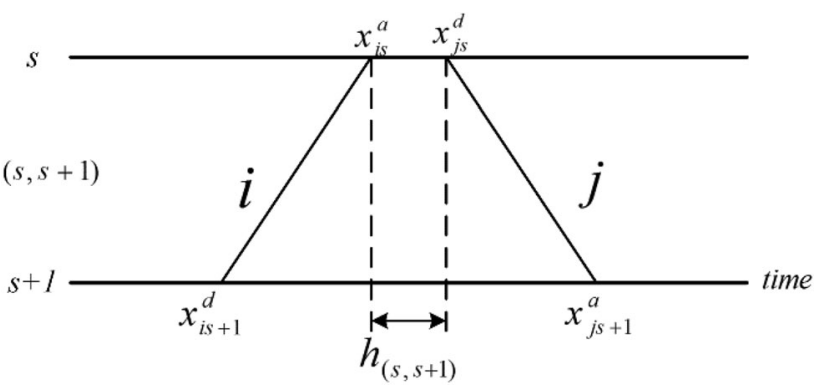

Fig. 6 Outbound-inbound or inbound-outbound trains' graph in block section $(s, s+1)$

lines. Therefore, urban and suburban rail networks can easily exploit the proposed model.

$$
\begin{aligned}
& N \cdot B_{i j(s, s+1)}+x_{i s+1}^{d} \geq x_{j s+1}^{a}+h_{(s, s+1)} \\
& N \cdot\left(1-B_{i j(s, s+1)}\right)+x_{j s}^{d} \geq x_{i s}^{a}+h_{(s, s+1)} \\
& \quad \text { for } s \in S, i>k \in K, \text { and } j \leq k \in K
\end{aligned}
$$

\subsubsection{Constraints of trains' timing and speed}

This group of constraints checks the trains' travel time and speed. The first major constraint is related to tractive force and resistance. To achieve the desired speed and to reliably complete the run, the required tractive force of train $i$ in block section $(s, s+1)$ should be greater than the running resistance. Equation 14 controls this constraint.

$T_{i(s, s+1)}^{f}>R_{i(s, s+1)}, \quad$ for $i \in K$, and $s \in S, s \neq D$

Another critical constraint in this group is a continuous speed limit and the locomotive/train maximum speed, which many train scheduling models neglect. In the train scheduling problem, the speed of trains should be set higher than the continuous speed; otherwise, low speed will cause the engine locomotive to warm up and will eventually damage the locomotive. Furthermore, each locomotive has a maximum speed limit constrained by its maximum power output. These constraints are represented by Eq. 15 . $v_{i}^{c} \leq v_{i(s, s+1)} \leq v_{i}^{\max }, \quad$ for $i \in K$, and $s \in S, s \neq D$

Notably, on some railroads, route conditions may prevent the train from reaching the maximum speed possible. Thus, the utmost train speed may be less than the maximum speed of the locomotive.

The arrival time of a train at the station is proportional to the departure time of the train from the previous station and the train's speed in the desired block section. Accordingly, it is necessary to consider constraints 16 and 17 in the model. 
$x_{i s+1}^{a}=x_{i s}^{d}+\frac{l_{(s, s+1)}}{v_{i(s, s+1)}}, \quad$ for $i \leq k \in K$, and $s \in S, s \neq D$

$x_{i s}^{a}=x_{i s+1}^{d}+\frac{l_{(s, s+1)}}{v_{i(s, s+1)}}$,

for $i>k \in K$, and $s \in S, s \neq D$

$v_{i(s, s+1)}$ is the economical speed in block section $(s, s+$ 1). The proposed model tries to optimize the train energy consumption in the desired block by determining its optimal speeds. This speed is an optimal average speed in a block that can vary from block to block. Because each block section has different conditions and the model decides on the optimal speed based on these conditions, the length of the blocks affects the accuracy of the model results. Figure 7 makes this more understandable. In Fig. 7a, the rail route of length $L$ between the two real stations is divided into one block, and in Fig. 7b, this route is sectioned into two blocks. As shown in Fig. 7, assume that there are two grades 3\%o and 5\%o along this rail route. Therefore, since the whole route is one block, the model for the example shown in Fig. 7a considers the largest grade (ruling grade: 5\%o) to model the route conditions and provides an economical speed for the route. By sectioning the rail route into two blocks (Fig. 7b), the model examines energy consumption in two sections and considers grade $3 \%$ to formulate the route conditions of block section $(s, s$ $+1)$ and grade $5 \%$ for block section $(s+1, s+2)$ and offers two optimal speeds to suit the condition of the rail route. As a result, by increasing the number of blocks in a rail route, the accuracy of route details in the model will intensify, and the model will provide more accurate results of energy consumption and optimal speeds. Therefore, by sectioning the rail route into shorter blocks, the model can achieve the optimal speed profile between the two main stations for use in ATO. Thereby, using the proposed model, in micro level, the railways will be able to assess the impact of the length and number of blocks on the rail route capacity, traffic, and energy consumption. The railway determines the characteristics of the blocks based on the route and fleet conditions and then applies them in the proposed model, and finally, according to the model results, selects the best conditions with the minimum travel time and energy consumption.

Constraints 16 and 17 and objective functions (3) and (10) act as an energy consumption controller and prevent high energy consumption by trains. Since stockholder satisfaction has a direct relationship with travel time, the model should reduce the value of $l_{(s, s+1)} / v_{i(s, s+1)}$. In other words, it is necessary to reduce the travel time by increasing the speed of the train. Increasing the speed will raise the resistance and, as a result, the energy consumption

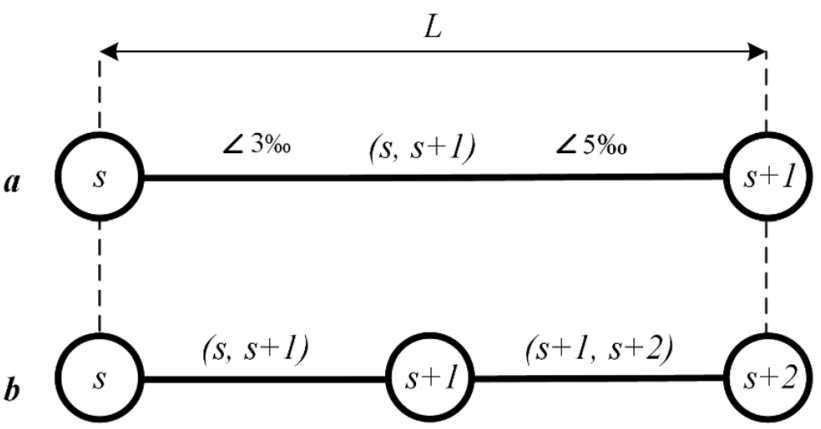

Fig. 7 The role of blocks in the model; a railroad with one block, b railroad sectioned into two blocks

to overcome the resistance. Therefore, constraints 16 and 17 and the model's objective functions intelligently control energy consumption by limiting the train speed, thus avoiding prolonging the travel time.

Equation 18 prevents the dispatch of trains before the earliest allowable departure time. If a train is to arrive at a predetermined time, Eq. 19 will prevent trains from being accepted after the latest scheduled arrival time.

$x_{i O}^{d} \geq y_{i O}^{d}, \quad$ for $i \in K$, and $O \in S$

$x_{i D}^{a} \leq y_{i D}^{a}, \quad$ for $i \in K$, and $D \in S$

Some of the trains at the intermediate stations spend the time to provide some services to passengers and goods. Constraint 20 ensures scheduled stops for trains at the stations.

$x_{i s}^{d} \geq x_{i s}^{a}+s t_{i s}, \quad$ for $i \in K$, and $s \in S, s \neq O, D$

If there is no planned stop for a train at a station, the value of $s t_{i s}$ for the train at the desired station will be zero. As described in Fig. 1, some of the stations in the proposed model are hypothetical stations where trains cannot cross, overtake, or stop. At such stations, $s t_{i s}=0$, and Eq. 20 will change to $x_{i s}^{d}=x_{i s}^{a}$. This change, in addition to banning stops at hypothetical stations, will automatically prevent trains from crossing and overtaking at such stations because, in this case, the train must enter the next block immediately, and this will prevent another train from entering the block and, thus, prevent the trains from overtaking or crossing at the hypothetical stations.

\section{Proposed Mathematical Model}

\subsection{Multi-Objective Train Scheduling Model}

Objective function 3 tries to reduce the train's travel time in a block by increasing the speed, while objective function 10 controls the train's energy consumption in a block by decreasing the speed. Therefore, along with the origin- 
Table 4. Characteristics of the locomotives

\begin{tabular}{lll}
\hline Information & Freight locomotive & Passenger locomotive \\
\hline Wheel arrangement & Co-Co & Bo-Bo \\
Power (hp) & 4000 & 2500 \\
Continuous speed $(\mathrm{km} / \mathrm{h})$ & 30 & 25 \\
Maximum speed $(\mathrm{km} / \mathrm{h})$ & 90 & 120 \\
Weight $(\mathrm{t})$ & 120 & 80 \\
Efficiency rate & $80 \%$ & $80 \%$ \\
\hline
\end{tabular}

destination stations of the rail route and per train, there are two objective functions, shown in Eqs. 21 and 22:

Min $\quad x_{i D}^{a}-x_{i O}^{d}, \quad$ for $i \in K$

$\operatorname{Max} \sum_{\substack{s \in S \\ s \neq D}}\left(T_{i(s, s+1)}^{f}-R_{i(s, s+1)}\right), \quad$ for $i \in K$

The objective function can be summed up to optimize the travel time and energy consumption of each train. The objective function is defined for each train as fractional objective function 23 :

$\operatorname{Min} \quad z_{i}=\frac{x_{i D}^{a}-x_{i O}^{d}}{\sum_{\substack{s \in S \\ s \neq D}}\left(T_{i(s, s+1)}^{f}-R_{i(s, s+1)}\right)}, \quad$ for $i \in K$

To minimize fractional objective function 23 , it is necessary to minimize the numerator (travel time) and maximize the denominator (subtraction of tractive force and resistance). Thus, fractional objective optimization function 23 will meet the objectives of the proposed model. Model 24 proposes a multi-objective train scheduling model that reduces the trains' travel time, stops, and energy consumption by economical speed determination.

$$
\text { Min } z_{i}=\frac{x_{i D}^{a}-x_{i O}^{d}}{\sum_{\substack{s \in S \\ s \neq D}}\left(T_{i(s, s+1)}^{f}-R_{i(s, s+1)}\right)}, \quad \text { for } i \in K
$$

\subsection{Fuzzy multi-objective train scheduling model}

Most multi-objective methods require interaction with experts and the user's preferences [55], and this will lead to challenges in determining the optimal solution [56]. This is due to differences in the desires and interests of different users. Fuzzy logic can provide a non-interactive approach to solve multi-objective optimization problems. Therefore, this method eliminates the need for receiving the opinions and preferences of experts and users to determine the final solution. Accordingly, this paper proposes a new fuzzy method originating in studies by Chakraborty and Gupta [57] and Youness et al. [58] for solving model 24. The concept of fuzzy sets was first expressed in 1937 and was called ambiguity. Then, in 1965, Professor Lotfi Zadeh published a paper entitled "Fuzzy sets" [59, 60]. Lotfi Zadeh states that "Membership in a fuzzy set is not a certain or uncertain issue, but is expressed as the degree of membership" [59]. A number in the interval $[0,1]$ determines the degree of membership in fuzzy sets. Suppose $X$ is a space of positive real values in relation to a variable, and $x$ is a member of $X$. The fuzzy set $A$ in $X$ is defined by Eq. 25 [59] where $\mu_{A}$ is the membership function, and $M$ is the membership space. $M$ usually takes the interval $[0,1]$.

$$
\begin{gathered}
A:\left\{\left(x, \mu_{A}(x)\right) \mid x \in X\right\} \\
\text { s.t }: \quad \mu_{A}: X \rightarrow M
\end{gathered}
$$

In the proposed model, by transforming the objective functions into fuzzy sets, the multi-objective model turns into a fuzzy single-objective model. In this case, the membership function represents the degree of satisfaction of the objective function. Bellman and Zadeh [61] and Lai and Hwang [62] showed that if there exist $n$ fuzzy objectives $\tilde{G}_{1}, \ldots, \tilde{G}_{n}$, the decision vector, including the intersection of objectives, is expressed in the form of Eq. 26:

$\tilde{D}=\tilde{G}_{1} \cap \tilde{G}_{2} \cap \ldots \cap \tilde{G}_{n}$

Since the Min operator defines the intersection of fuzzy sets, we rewrite Eq. 26 as Eq. 27, in which $A_{i}(x)$ is a generalized representation for the membership functions of the objectives.

$$
\begin{aligned}
D(x) & =\min \left(G_{1}(x), G_{2}(x), \ldots, G_{n}(x)\right)=\min \left(G_{i}(x)\right) \\
& =\min \left(A_{i}(x)\right)
\end{aligned}
$$

To use fuzzy mathematical programming for solving the proposed multi-objective model, we press the values of the objective functions $z_{i}$ into the interval $[0,1]$. As mentioned before, we need to increase the difference between tractive forces and resistance to reduce energy consumption. As a result, to decrease the value of objective function 23 to $<1$, the model should increase the denominator of this objective function, which precisely follows the paper's purpose. Therefore, we add constraint 28 to the proposed fuzzy model.

$0 \leq z_{i} \leq 1, \quad$ for $i \in K$

Consequently, objective functions $z_{i}$ will be a fuzzy set. Figure 8 illustrates the linear membership degree function 


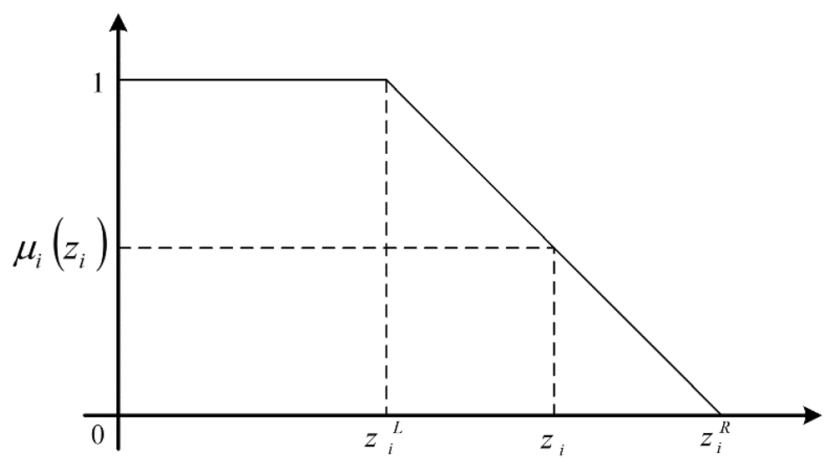

Fig. 8. Linear membership function for the Min objective function

for the Min objective function in which $z_{i}^{L}$ and $z_{i}^{R}$ are values of the objective function $z_{i}$, respectively, having membership degrees of 1 and 0 [63,64].

Assuming $\mu_{i}\left(z_{i}\right)=\beta$, a convex combination of $z_{i}^{L}$ and $z_{i}^{R}$ formulates the objective function $z_{i}$, or $z_{i}=(1-\beta) \cdot z_{i}^{R}+\beta \cdot z_{i}^{L}$, where $0 \leq \beta \leq 1$. According to Bellman and Zadeh [61], the fuzzy decision-making model and the Max-Min operator, objective function 29 is a rewritten version of the objective function of model 24:

$\operatorname{Max}\left\{\tilde{z_{1}} \cap \tilde{z_{2}} \cap \ldots \cap \tilde{z_{m}} \cap \tilde{z_{\ldots}}=\operatorname{Min}_{i} \quad \mu_{i}\left(z_{i}\right)\right\}$

If Min $\mu_{i}\left(z_{i}\right)=(1-\beta) \cdot z_{i}^{R}+\beta \cdot z_{i}^{L}$, model 24 will change to model 30 .

$$
\begin{aligned}
\operatorname{Max} & \left\{(1-\beta) \cdot z_{i}^{R}+\beta \cdot z_{i}^{L}\right\} \\
\text { s.t }: \quad & z_{i} \geq(1-\beta) \cdot z_{i}^{R}+\beta \cdot z_{i}^{L}, \quad \text { for } i \in K \\
0 \leq & z_{i} \leq 1, \quad \text { for } i \in K \\
0 & \leq \beta \leq 1
\end{aligned}
$$$$
\text { Constraints } \quad(11)-(20)
$$

Since in model 30 , the value of all objective functions is in the interval $[0,1]$, we will have: $z_{j}^{L}=1$ and $z_{j}^{R}=0$. Therefore, model 31 is obtained according to model 30 . Model 31 is the proposed fuzzy model of this paper for a train scheduling problem to reduce the trains' travel time and energy consumption.

$\operatorname{Max} \beta$

$$
\begin{aligned}
\text { s.t : } \quad z_{i} \geq \beta, \quad \text { for } i \in K \\
0 \leq z_{i} \leq 1, \quad \text { for } i \in K \\
0 \leq \beta \leq 1
\end{aligned}
$$$$
\text { Constraints }(11)-(20)
$$

\section{Model Testing}

The proposed model was evaluated using real data from Iran's suburban railways. According to the information from the East Railway District of Iran, there is a 524-kmlong Tabas-Mashhad rail route in this area with five

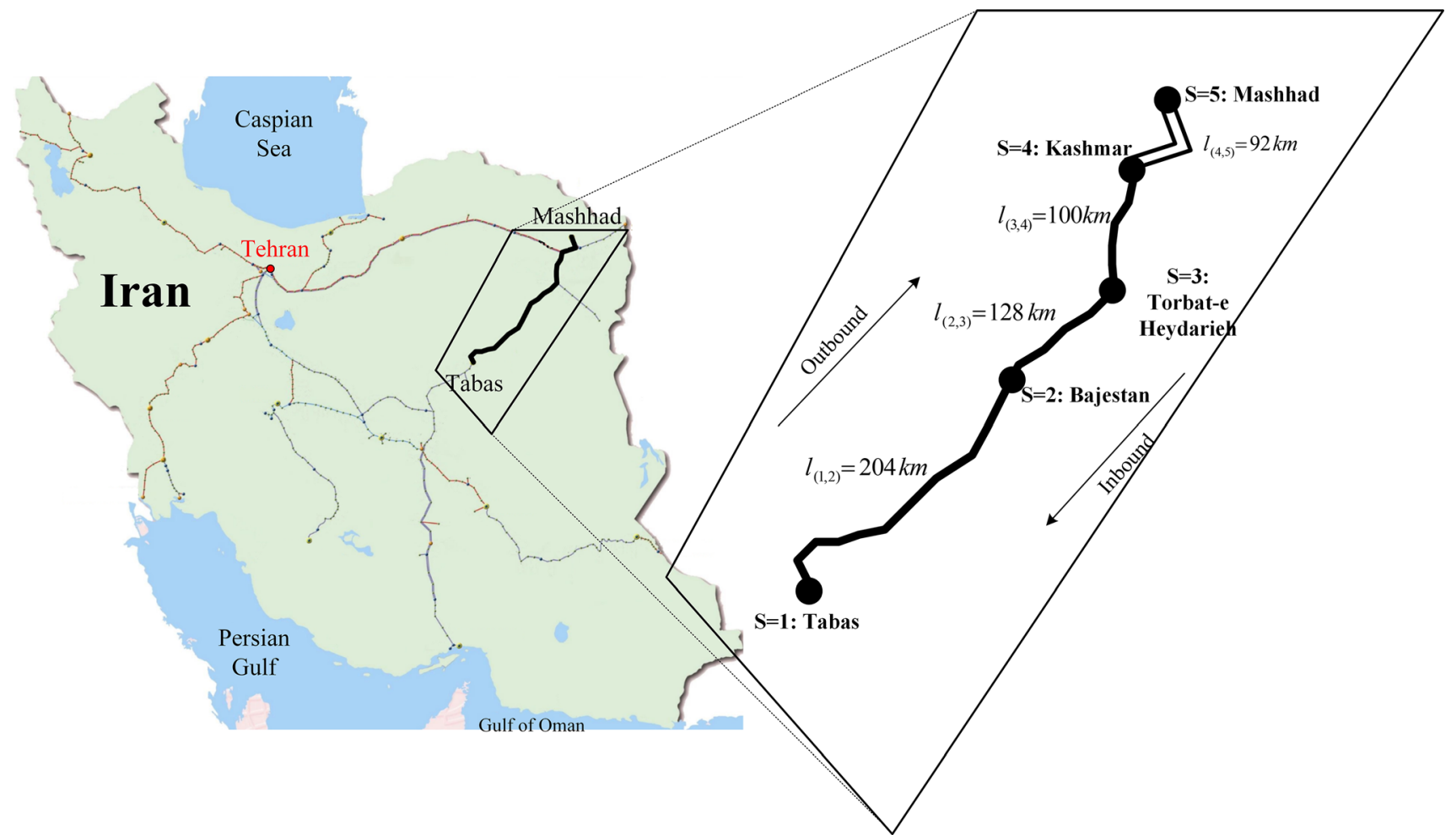

Fig. 9 Rail network in the real example 
Table 5 Information of trains' dispatch in the real example

\begin{tabular}{|c|c|c|c|c|c|c|c|c|}
\hline \multirow[t]{2}{*}{ Train type } & \multirow[t]{2}{*}{ Train no. } & \multirow[t]{2}{*}{ Origin station } & \multirow[t]{2}{*}{ Destination station } & \multicolumn{2}{|c|}{ Speed $(\mathrm{km} / \mathrm{h})$} & \multicolumn{3}{|c|}{ Scheduled stopping time (min) } \\
\hline & & & & $v_{c}^{i}$ & $v_{\max }^{i}$ & Station 2 & Station 3 & Station 4 \\
\hline Passenger & $\mathrm{T} 1$ & 1 & 4 & 25 & 105 & 15 & 15 & - \\
\hline Passenger & $\mathrm{T} 2$ & 1 & 5 & 25 & 105 & 15 & 15 & 15 \\
\hline Freight & $\mathrm{T} 3$ & 1 & 5 & 30 & 85 & 0 & 0 & 0 \\
\hline Freight & $\mathrm{T} 4$ & 1 & 3 & 30 & 85 & 0 & - & - \\
\hline Passenger & $\mathrm{T} 5$ & 5 & 1 & 25 & 105 & 15 & 15 & 15 \\
\hline Passenger & T6 & 4 & 1 & 25 & 105 & 15 & 15 & - \\
\hline Freight & $\mathrm{T} 7$ & 5 & 1 & 30 & 85 & 0 & 0 & 0 \\
\hline Freight & $\mathrm{T} 8$ & 3 & 1 & 30 & 85 & 0 & - & - \\
\hline
\end{tabular}

Table 6 Results of the proposed model with a 48-h time limit

\begin{tabular}{|c|c|c|c|c|c|c|c|c|c|c|c|}
\hline \multirow[t]{2}{*}{ Train no. } & \multicolumn{4}{|c|}{ Train economical speed at block sections $(\mathrm{km} / \mathrm{h})$} & \multicolumn{4}{|c|}{ Travel time at block sections (h) } & \multicolumn{3}{|c|}{ Stopping time at stations $(\mathrm{h})$} \\
\hline & $(1,2)$ & $(2,3)$ & $(3,4)$ & $(4,5)$ & $(1,2)$ & $(2,3)$ & $(3,4)$ & $(4,5)$ & 2 & 3 & 4 \\
\hline $\mathrm{T} 1$ & 25 & 25 & 25 & - & 8.16 & 5.12 & 4 & - & 0.25 & 0.25 & - \\
\hline $\mathrm{T} 2$ & 39.8 & 25 & 25 & 25 & 5.12 & 5.12 & 4 & 3.68 & 0.25 & 0.25 & 0.25 \\
\hline $\mathrm{T} 3$ & 40.7 & 30 & 30 & 30 & 5.01 & 4.27 & 3.33 & 3.07 & 0 & 0 & 0 \\
\hline $\mathrm{T} 4$ & 30 & 30 & - & - & 6.8 & 4.27 & - & - & 0 & - & - \\
\hline T5 & 75 & 25 & 25 & 25 & 2.72 & 5.12 & 4 & 3.68 & 14.45 & 0.68 & 0.25 \\
\hline T6 & 27.4 & 25 & 25 & - & 7.44 & 5.12 & 4 & - & 0.25 & 0.25 & - \\
\hline $\mathrm{T} 7$ & 48.5 & 30 & 30 & 30 & 4.2 & 4.27 & 3.33 & 3.07 & 0 & 0.5 & 0 \\
\hline $\mathrm{T} 8$ & 38.4 & 30 & - & - & 5.31 & 4.27 & - & - & 33.97 & - & - \\
\hline \multicolumn{5}{|c|}{ Total time (h) } & \multicolumn{4}{|l|}{118.48} & \multicolumn{3}{|l|}{51.6} \\
\hline
\end{tabular}

stations $(S=\{1,2,3,4,5\})$ and four main block sections (Fig. 8). The Kashmar-Mashhad route is double-lined and $92 \mathrm{~km}$ long, and the Tabas-Kashmar is single-lined and $432 \mathrm{~km}$ long. The Iranian railway considers the distance between the two main stations as a block. Figure 9 shows the stations, blocks, and block lengths [65].

In this rail route, a maximum of eight freight and passenger trains travel in a 2-day cycle. In other words, the journey of these eight trains is repeated every 2 days. The Co-Co diesel-electric and the Bo-Bo diesel-electric locomotives, respectively, are used to transport freight and passenger trains. Table 4 presents the characteristics of locomotives to carry the trains.

In this example, the trains running on the TabasMashhad route are assumed to be the outbound trains, and the ones running on the Mashhad-Tabas route are taken to be the inbound trains (Fig. 9). Table 5 presents the trains' information and their time of dispatch.
The passenger trains consist of seven wagons weighing 60 tons and a four-axis arrangement, and freight trains consist of 15 wagons with a weight of 80 tons and four axles. Freight trains T4 and T7 are empty trains with a weight of 20 tons for each wagon. The ruling grades in block sections $(1,2),(2,3),(3,4)$, and $(4,5)$ for outbound trains are $8 \%$, $9 \%, 10 \%$, and $5 \%$, and for inbound trains, $11 \% 0,7 \%$, 9\%o, and 7\%o, respectively, and $h_{(s, s+1)}=$ $15 \mathrm{~min}$ for $s=1,2,3,4$ [65].

Equation 4 computes the tractive force for the trains as follows:

$T_{i(s, s+1)}^{f}=\frac{270 P o_{i} \rho_{i}}{v_{i(s, s+1)}}=\frac{540000}{v_{i(s, s+1)}} \quad$ For passenger trains

$T_{i(s, s+1)}^{f}=\frac{270 P o_{i} \rho_{i}}{v_{i(s, s+1)}}=\frac{864000}{v_{i(s, s+1)}} \quad$ For freight trains

The Davis resistance for freight and passenger locomotives is as follows by using Eq. 6 and Table 3: 
$R_{i(s, s+1)}^{c}=104.8+0.7448 v_{i(s, s+1)}+0.055719\left(v_{i(s, s+1)}\right)^{2}$

For passenger loco.

$R_{i(s, s+1)}^{c}=157.2+1.1172 v_{i(s, s+1)}+0.055719\left(v_{i(s, s+1)}\right)^{2}$

For freight loco.

The Davis resistance for freight and passenger wagons is calculated as follows:

$R_{i(s, s+1)}^{c}=642.6+3.9102 v_{i(s, s+1)}+0.0512316\left(v_{i(s, s+1)}\right)^{2}$

For passenger wagons

$R_{i(s, s+1)}^{c}=1572+16.74 v_{i(s, s+1)}+0.121776\left(v_{i(s, s+1)}\right)^{2}$

For freight wagons

$R_{i(s, s+1)}^{c}=978+4.185 v_{i(s, s+1)}+0.121776\left(v_{i(s, s+1)}\right)^{2}$

For empty freight wagons

Therefore, according to Eq. 9, resistance against the movement of freight and passenger trains in various block sections will be calculated as follows:

$$
\begin{aligned}
R_{i(s, s+1)}= & 747.4+4.655 v_{i(s, s+1)}+0.1069506\left(v_{i(s, s+1)}\right)^{2} \\
& +500 \alpha_{(s, s+1)} \forall s \in S, s \neq D, \text { For passenger trains } \\
R_{i(s, s+1)}= & 1729.2+17.8572 v_{i(s, s+1)}+0.177495\left(v_{i(s, s+1)}\right)^{2} \\
& +1320 \alpha_{(s, s+1)} \forall s \in S, s \neq D, \text { For freight trains } \\
R_{i(s, s+1)}= & 1135.2+5.3022 v_{i(s, s+1)}+0.177495\left(v_{i(s, s+1)}\right)^{2} \\
& +420 \alpha_{(s, s+1)} \forall s \in S, s \neq D, \text { For empty freight trains }
\end{aligned}
$$

The proposed model was implemented using Lingo optimization software. The design of the proposed model is such that it determines the economical speed of trains according to the time available for train travel. In other words, the proposed model adjusts the speed of the trains in such a way as to balance between available time constraints and the energy consumption as low as possible. In the rail operations of the area in question, due to the long blocks and the currently used manual time table for moving the trains, the trains' travel time is long, which increases the fuel consumption, passenger dissatisfaction, and the unused capacity of rail routes, and ultimately reduces resource efficiency. With the assumption of no changes in any realworld constraints (with a 48-h time limit), the proposed model can provide an optimal strategy for Iran's railway. In this strategy, train movement will be limited to 2 days, and energy consumption will be optimized. Therefore, constraint 19 is as follows: $x_{i D}^{a} \leq 48$, for $i \in K$. Table 6 presents the results of the proposed model for a real example, with a 48-h time limit and $\beta=0.322 \mathrm{E}-2$. Figure 10 also depicts the trains' graph.

Since energy consumption is directly related to the resistance along the route and the duration of the tractive force use [29, 66], Eq. 32 is formulated to estimate energy consumption. Equation 32 represents the energy consumption coefficient (ECC) for each train in which $l_{(s, s+1)} / v_{i(s, s+1)}$ indicates the travel time of train $i$ in block section $(s, s+1)$. Railways can determine the energy cost by multiplying the energy cost rate of their rail network (per locomotive power or distance) in Eq. 32. Thus, ECC is

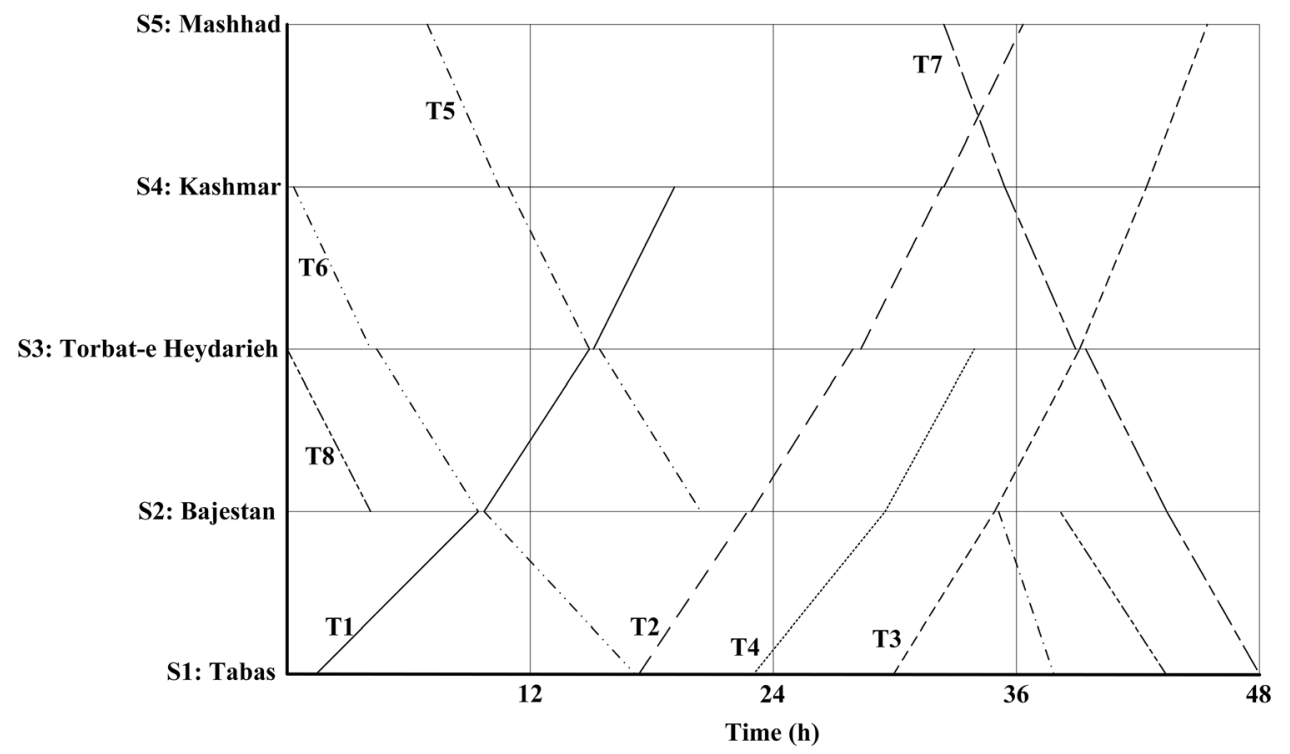

Fig. 10 Trains' graph with a 48-h time limit 
Table 7 Results of the proposed model with a 33-h time limit

\begin{tabular}{|c|c|c|c|c|c|c|c|c|c|c|c|}
\hline \multirow[t]{2}{*}{ Train no. } & \multicolumn{4}{|c|}{ Train economical speed at block sections $(\mathrm{km} / \mathrm{h})$} & \multicolumn{4}{|c|}{ Travel time at block sections (h) } & \multicolumn{3}{|c|}{ Stopping time at stations $(\mathrm{h})$} \\
\hline & $(1,2)$ & $(2,3)$ & $(3,4)$ & $(4,5)$ & $(1,2)$ & $(2,3)$ & $(3,4)$ & $(4,5)$ & 2 & 3 & 4 \\
\hline $\mathrm{T} 1$ & 89.6 & 35.25 & 25 & - & 2.28 & 3.63 & 4 & - & 2.24 & 3.82 & - \\
\hline $\mathrm{T} 2$ & 89.6 & 35.25 & 25 & 25 & 2.28 & 3.63 & 4 & 3.68 & 3.6 & 4.19 & 0.25 \\
\hline $\mathrm{T} 3$ & 35.5 & 30 & 30 & 30 & 5.75 & 4.27 & 3.33 & 3.07 & 0 & 3.7 & 0 \\
\hline $\mathrm{T} 4$ & 41.8 & 30 & - & - & 4.9 & 4.27 & - & - & 1.67 & - & - \\
\hline T5 & 75 & 37 & 25 & 25 & 2.72 & 3.46 & 4 & 3.68 & 2.54 & 13.18 & 0.25 \\
\hline T6 & 75 & 37 & 25 & - & 2.72 & 3.46 & 4 & - & 1.8 & 0.51 & - \\
\hline $\mathrm{T} 7$ & 42 & 30 & 30 & 30 & 4.9 & 4.27 & 3.33 & 3.07 & 0.5 & 0.56 & 0 \\
\hline $\mathrm{T} 8$ & 35.5 & 30 & - & - & 5.75 & 4.27 & - & - & 0.78 & - & - \\
\hline \multicolumn{5}{|c|}{ Total time $(\mathrm{h})$} & \multicolumn{4}{|l|}{98.66} & \multicolumn{3}{|l|}{39.59} \\
\hline
\end{tabular}

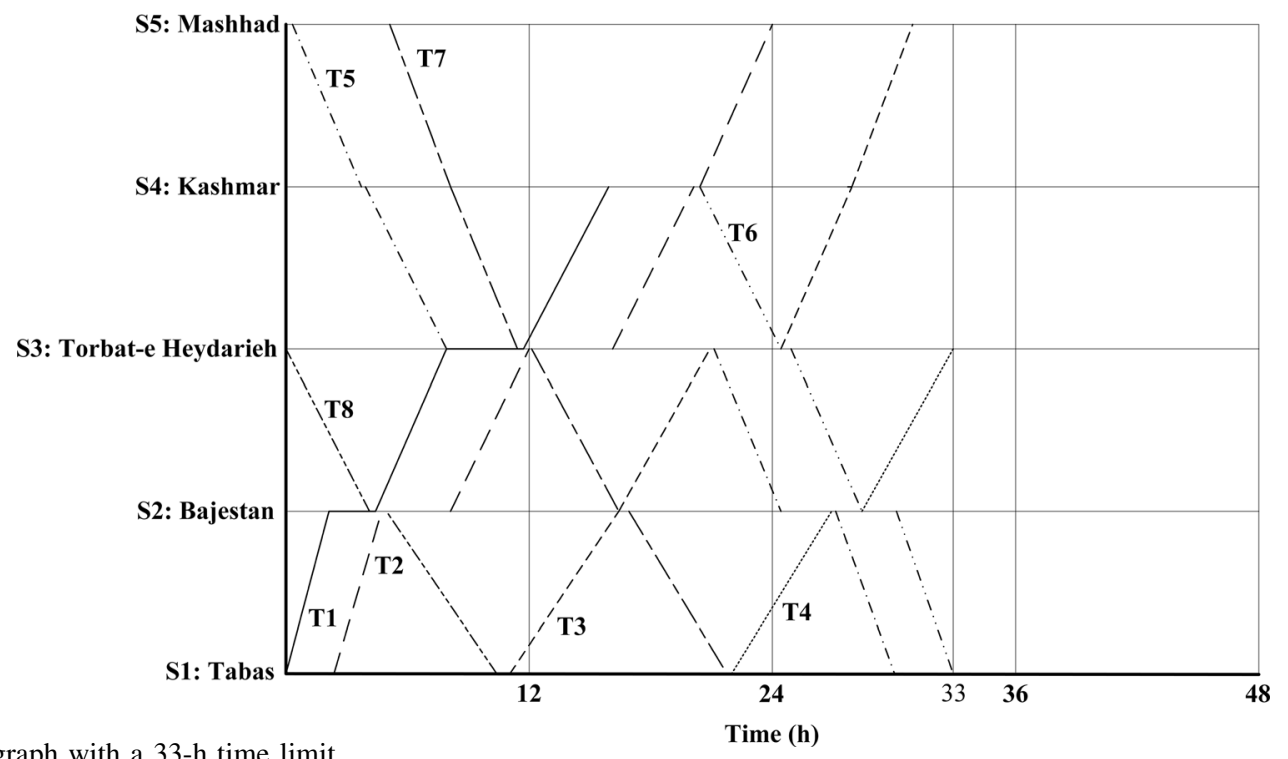

Fig. 11 Trains' graph with a 33-h time limit

Time (h)

a good measure for assessing energy consumption in different railways with different energy cost rates.

$\mathrm{ECC}^{\mathrm{i}}=\sum_{\substack{s \in S \\ s \neq D}}\left(R_{i(s, s+1)} l_{(s, s+1)}+T_{i(s, s+1)}^{f} \frac{l_{(s, s+1)}}{v_{i(s, s+1)}}\right)$,

for $i \in K$

According to the results of the proposed model with a 48-h time limit, the $E C C=29.46 \mathrm{E}+6$ units, and the trains' total travel time is $170.08 \mathrm{~h}$. The amount of energy consumed is the optimal amount achieved due to the limitations of the problem. The model, according to the available time limit, adjusts the speed of the trains to minimize energy consumption. Nevertheless, as shown in Table 6 and Fig. 10, the 48-h scheduling for trains resulted in inefficient use of rail routes' capacity. Long journeys and stops can lead to dissatisfaction among passengers and goods owners. This inefficiency is now also observed in the real rail network. The proposed model could provide another scenario for the planning of trains. In the following, we implemented the proposed model with a 33-h time limit. Table 7 and Fig. 11 present the results of the implementation of the proposed model by applying $x_{i D}^{a} \leq 33, \quad$ for $i \in K$ and determining $\beta=0.221 \mathrm{E}-2$.

In this scenario, $E C C=29.46 \mathrm{E}+6$, and the total travel time of the trains is $138.25 \mathrm{~h}$. As we see, the total travel time against the 48-h time limit scenario has improved by $19 \%$, while the energy consumption ratio has not changed. The ECC is the same in the two scenarios of implementation of the proposed model; this reflects the correct performance of the model in optimizing both the speed of trains and energy consumption. In the $33-\mathrm{h}$ time limit 


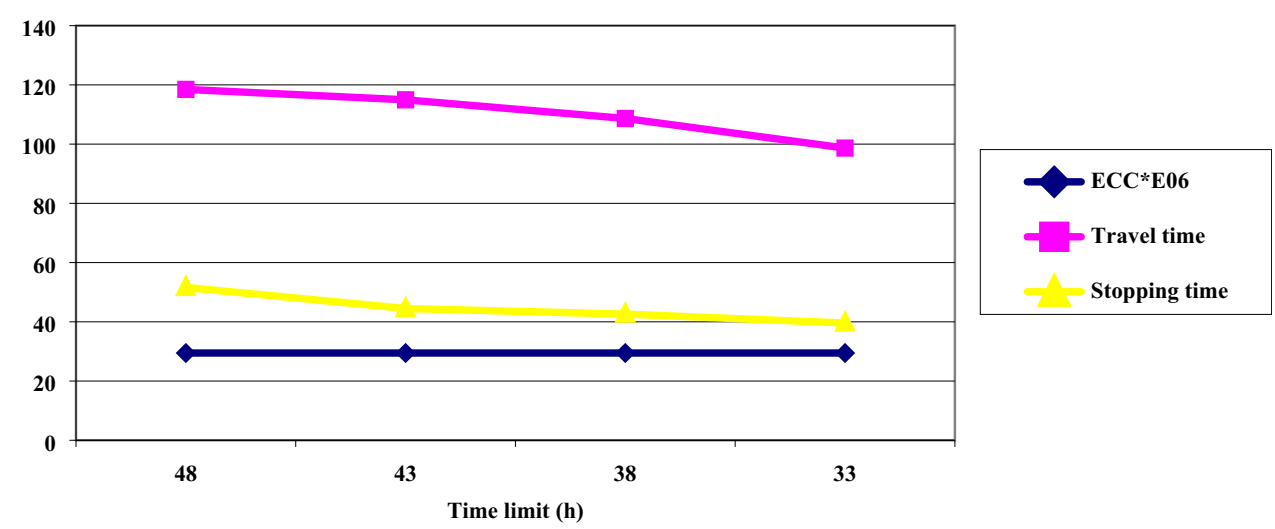

Fig. 12 The results of various scenarios

scenario, with the speed of trains increasing, the travel time of the trains has decreased (increase in the second part of Eq. 32), but this also resulted in an increase in running resistance over distance (decrease in the first part of Eq. 32); this is exactly the opposite of what happened in the 48-h time limit scenario. Therefore, the proposed model, with a trade-off between the resistance and the required tractive force, adjusts the speed in different states in such a way as to optimize energy consumption. Also, in the new scenario, the proposed model provides a 15-h empty capacity for the Iranian railway (Fig. 11). The railway can use this empty capacity to move more trains and thus use more of the rail routes capacity.

Figure 12 displays the results of implementing the proposed model with different time limitations. Based on the results of this figure, $E C C$ is the same in various scenarios, but total travel time differs. Although there are various economical speeds in different scenarios, energy consumption is at least possible, and this ensures the correct performance of the proposed model. The proposed model, with a 33-h time limit, offers the lowest travel and stopping time.

\section{Conclusion and Suggestions}

Train scheduling, which determines the arrival and departure time of trains at the stations on the macroscopic level, is one of the most important tasks undertaken by railways to make efficient use of infrastructure. However, considering the microscopic level is crucial in providing a stable and operational timetable. Consequently, given the very costly infrastructure of railroads, it is vital to provide a reliable train scheduling model that integrates the macroscopic and microscopic levels. The present paper introduced a new fuzzy multi-objective train scheduling model by combining micro and macro levels, using a novel perspective, and taking into account running resistance and the tractive force required to move the trains.

The proposed model considered train travel time as a determinant of the satisfaction of passengers and goods owners, and energy consumption as a factor determining the railway's satisfaction. From the viewpoint of passengers and goods owners, the railways should satisfy them with increasing the speed of trains, thereby reducing the trains' travel time and ensuring punctuality. The increase in speed will lead to grown resistance during the train movement, thereby raising energy consumption and, ultimately, railway dissatisfaction. Therefore, the railway tries to reduce energy consumption by reducing train speed.

Therefore, the proposed model followed two opposing objectives: (1) increasing the satisfaction of passengers and owners with raising train speed and (2) reducing energy consumption by decreasing train speed. The determining factors of energy consumption in the railways are the tractive force and running resistance. Increasing the difference between these two factors, which are proportional to the speed of trains, will result in lower energy consumption. The proposed model uses this new perspective to formulate the objective function of energy consumption. As a result, the model, using fuzzy mathematical programming and a trade-off between the trains' energy consumption and the travel time, and given the available time limit, provides the economical speed in different block sections to achieve the minimum energy consumption and the satisfaction of the rail transport parties. In ATO systems, determining the economical speed and then developing a train speed profile that can ensure punctuality and optimal energy consumption is essential. Therefore, the suggested model dealing with an interesting topic contributes to a more energy-efficient and sustainable railway system.

We implemented this model with a real example of the Iranian railway. The results revealed that the model 
improved the total travel time of trains by at least $19 \%$ by keeping the energy consumption constant and increasing the capacity of the rail route. The various analyses of the proposed model in the form of scenarios with different time constraints confirmed the validity of the model. By reducing the time available, the model guaranteed punctuality by the higher speed, but this trend accompanied an increase in energy consumption. However, the proposed model determined the amount of energy consumed to be as low as possible by balancing the duration of the train tractive force and the running resistance in block sections. If the speed of the train increased and the travel time decreased, the duration of applying the tractive force would be reduced, but the resistance would grow. In the event of a reduction in the speed of the train and an increase in travel time, the duration of applying the tractive force and resistance would increase and decrease, respectively. Thus, in the case of a decrease or increase in the speed of the train, in the proposed model, the weighted sum of the two factors of energy consumption would remain almost constant.

The proposed micro-macro multi-objective train scheduling model has little need for input parameters, and the results demonstrated the success of this research. Based on the researchers' chosen point of view, modeling and presenting an efficient model are among the most crucial steps in problem-solving. Future research directions include implementing the model in large real examples, providing fast and efficient algorithms such as metaheuristic algorithms for the proposed model, modifying the model to determine the optimal length and number of blocks to reduce energy consumption, investigating the model's impact on the capacity of railway lines, and examining the application and effect of the proposed model in ATO systems. Implementing the model results in a practical environment, comparing it with the reference timetable, and providing a framework of delay management in stopping and running time can be other interesting topics for applied studies.

\section{Acknowledgements Not applicable.}

Authors' contributions The author developed the theory and performed the computations, verified the analytical methods, discussed the results, carried out the sequence alignment and wrote the manuscript.

\section{Funding Not applicable.}

Data Availability The author declares that the materials described in the paper, including codes, databases and all relevant raw data, are freely available to any scientist wishing to use them.

\section{Declarations}

Conflict of interest The author declares that they have no conflict of interest.

Open Access This article is licensed under a Creative Commons Attribution 4.0 International License, which permits use, sharing, adaptation, distribution and reproduction in any medium or format, as long as you give appropriate credit to the original author(s) and the source, provide a link to the Creative Commons licence, and indicate if changes were made. The images or other third party material in this article are included in the article's Creative Commons licence, unless indicated otherwise in a credit line to the material. If material is not included in the article's Creative Commons licence and your intended use is not permitted by statutory regulation or exceeds the permitted use, you will need to obtain permission directly from the copyright holder. To view a copy of this licence, visit http://creativecommons. org/licenses/by/4.0/.

\section{References}

1. Yin J, Tang T, Yang L, Xun J, Huang Y, Gao Z (2017) Research and development of automatic train operation for railway transportation systems: a survey. Transp Res Part C Emerg Technol 85:548-572

2. Jin B, Feng X, Wang Q, Sun P, Fang Q Train. Scheduling method to reduce substation energy consumption and peak power of metro transit systems. Transp Res Rec, 0361198120974677

3. Liao J, Zhang F, Zhang S, Yang G, Gong C (2021) Energy-saving optimization strategy of multi-train metro timetable based on dual decision variables: a case study of Shanghai Metro line one. J Rail Transp Plan Manag 17:100234

4. Yang X, Li X, Ning B, Tang T (2016) A survey on energyefficient train operation for urban rail transit. IEEE Trans Intell Transp Syst 17(1):2-13

5. Fernández PM, Sanchís IV, Yepes V, Franco RI (2019) A review of modelling and optimisation methods applied to railways energy consumption. J Clean Prod 222:153-162

6. Albrecht A, Howlett P, Pudney P, Vu X, Zhou P (2016) The key principles of optimal train control-part 2: existence of an optimal strategy, the local energy minimization principle, uniqueness, computational techniques. Transp Res Part B Methodol 94:509-538

7. Wang Y, Zhang M, Ma J, Zhou X (2016) Survey on driverless train operation for urban rail transit systems. Urban Rail Transit 2(3-4):106-113

8. Bešinović N, Goverde RM, Quaglietta E, Roberti R (2016) An integrated micro-macro approach to robust railway timetabling. Transp Res Part B Methodol 87:14-32

9. Scheepmaker GM, Goverde RM, Kroon LG (2017) Review of energy-efficient train control and timetabling. Eur J Oper Res 257(2):355-376

10. Liebchen $C$ (2008) The first optimized railway timetable in practice. Transp Sci 42(4):420-435

11. Barrena E, Canca D, Coelho LC, Laporte G (2014) Exact formulations and algorithm for the train timetabling problem with dynamic demand. Comput Oper Res 44:66-74

12. Cacchiani V (2009) Models and algorithms for combinatorial optimization problems arising in railway applications. Springer

13. Cacchiani V, Furini F, Kidd MP (2016) Approaches to a realworld train timetabling problem in a railway node. Omega 58:97-110. https://doi.org/10.1016/j.omega.2015.04.006

14. Cacchiani V, Caprara A, Fischetti M (2012) A Lagrangian heuristic for robustness, with an application to train timetabling. Transp Sci 46(1):124-133 
15. Zhang H, Jia L, Wang L, Xu X (2019) Energy consumption optimization of train operation for railway systems: algorithm development and real-world case study. J Clean Prod 214:1024-1037

16. Yang L, Li K, Gao Z (2009) Train timetable problem on a singleline railway with fuzzy passenger demand. IEEE Trans Fuzzy Syst 17(3):617-629

17. Cacchiani V, Caprara A, Toth $\mathrm{P}$ (2008) A column generation approach to train timetabling on a corridor. 4OR 6(2):125-142

18. Odijk MA (1996) A constraint generation algorithm for the construction of periodic railway timetables. Transp Res Part B Methodol 30(6):455-464

19. Yaghini M, Momeni M, Sarmadi M (2015) A hybrid solution method for fuzzy train formation planning. Appl Soft Comput 31:257-265

20. Yang L, Zhou X, Gao Z (2014) Credibility-based rescheduling model in a double-track railway network: a fuzzy reliable optimization approach. Omega 48:75-93

21. Chow AH, Li Y (2014) Robust optimization of dynamic motorway traffic via ramp metering. IEEE Trans Intell Transp Syst 15(3):1374-1380

22. Li X, Yang L, Li K, Gao Z (2011) 3E-Model for temporary passenger train scheduling problem. Inf Int Interdiscip $\mathbf{J}$ 14(2):373-389

23. Chow AH, Pavlides A (2018) Cost functions and multi-objective timetabling of mixed train services. Transp Res Part A Policy Pract 113:335-356

24. Pavlides A, Chow AH (2018) Multi-objective optimization of train timetable with consideration of customer satisfaction. Transp Res Rec, 0361198118777629

25. UIC (2012) Moving towards Sustainable Mobility: European Rail Sector Strategy 2030 and beyond. International Union of Railways (UIC) and Community of European Railway and Infrastructure Companies (CER), Paris, France

26. UIC (2018) Sustainable Development: Making railways greener, quieter and more energy efficient. International Union of Railways (UIC), Paris, France

27. Higgins A, Kozan E, Ferreira L (1996) Optimal scheduling of trains on a single line track. Transp Res Part B Methodol 30(2):147-161

28. Ghoseiri K, Szidarovszky F, Asgharpour MJ (2004) A multiobjective train scheduling model and solution. Transp Res Part B Methodol 38(10):927-952

29. Li X, Wang D, Li K, Gao Z (2013) A green train scheduling model and fuzzy multi-objective optimization algorithm. Appl Math Model 37(4):2063-2073

30. Parbo J, Nielsen OA, Prato CG (2016) Passenger perspectives in railway timetabling: a literature review. Transp Rev 36(4):500-526

31. Sanchis IV, Zuriaga PS (2016) An energy-efficient metro speed profiles for energy savings: application to the Valencia metro. Transp Res Procedia 18:226-233

32. Li L, Zhang $X$ (2020) Integrated optimization of railway freight operation planning and pricing based on carbon emission reduction policies. J Clean Prod 263:121316

33. Huang Y, Yang L, Tang T, Cao F, Gao Z (2016) Saving energy and improving service quality: bicriteria train scheduling in urban rail transit systems. IEEE Trans Intell Transp Syst 17(12):3364-3379

34. Qi J, Yang L, Gao Y, Li S, Gao Z (2016) Integrated multi-track station layout design and train scheduling models on railway corridors. Transp Res Part C Emerg Technol 69:91-119. https:// doi.org/10.1016/j.trc.2016.05.020

35. Schlechte T, Borndörfer R, Erol B, Graffagnino T, Swarat E (2011) Micro-macro transformation of railway networks. J Rail Transp Plan Manag 1(1):38-48
36. Su S, Tang T, Roberts C (2015) A cooperative train control model for energy saving. IEEE Trans Intell Transp Syst 16(2):622-631

37. Kroon L, Maróti G, Helmrich MR, Vromans M, Dekker R (2008) Stochastic improvement of cyclic railway timetables. Transp Res Part B Methodol 42(6):553-570

38. Caprara A, Kroon L, Monaci M, Peeters M, Toth P (2007) Passenger railway optimization. Handb Oper Res Manag Sci 14:129-187

39. Zhou X, Zhong M (2007) Single-track train timetabling with guaranteed optimality: branch-and-bound algorithms with enhanced lower bounds. Transp Res Part B Methodol 41(3):320-341

40. Kroon LG, Peeters LW (2003) A variable trip time model for cyclic railway timetabling. Transp Sci 37(2):198-212

41. Liu RR, Golovitcher IM (2003) Energy-efficient operation of rail vehicles. Transp Res Part A Policy Pract 37(10):917-932

42. Peeters L (2003) Cyclic railway timetable optimization, vol EPS2003-022-LIS

43. Faieghi M, Jalali A (2014) Robust adaptive cruise control of high speed trains. ISA Trans 53(2):533-541

44. Ye H, Liu R (2016) A multiphase optimal control method for multi-train control and scheduling on railway lines. Transp Res Part B Methodol 93:377-393

45. Rajabighamchi F, Hajlou EMH, Hassannayebi E (2019) A multiobjective optimization model for robust skip-stop scheduling with earliness and tardiness penalties. Urban Rail Transit $5(3): 172-185$

46. Zhang Z, Wang C, Zhang W (2015) Status analysis and development suggestions on signaling system of Beijing rail transit. Urban Rail Transit 1(1):1-12

47. Liebchen C, Schachtebeck M, Schöbel A, Stiller S, Prigge A (2010) Computing delay resistant railway timetables. Comput Oper Res 37(5):857-868

48. Satish C, Agarwal M (2007) Railway engineering. Oxford University Press, Oxford

49. Davis WJ (1926) The tractive resistance of electric locomotives and cars. General Electric

50. AREA (1995) Manual for Railway Engineering 1995. American Railway Engineering Association

51. Hay WW (1982) Railroad engineering, vol 1. Wiley

52. Spiryagin M, Lee KS, Yoo HH (2008) Control system for maximum use of adhesive forces of a railway vehicle in a tractive mode. Mech Syst Signal Process 22(3):709-720

53. Dong H, Ning B, Cai B, Hou Z (2010) Automatic train control system development and simulation for high-speed railways. IEEE Circuits Syst Mag 10(2):6-18

54. Jafarian-Moghaddam AR, Yaghini M (2019) An effective improvement to main non-periodic train scheduling models by a new headway definition. Iran J Sci Technol Trans Civ Eng 43(4):735-745. https://doi.org/10.1007/s40996-018-0212-2

55. Miettinen K (2008) Introduction to multiobjective optimization: noninteractive approaches. In: Multiobjective optimization. Springer, pp 1-26

56. Marler RT, Arora JS (2004) Survey of multi-objective optimization methods for engineering. Struct Multidiscip Optim 26(6):369-395

57. Chakraborty M, Gupta S (2002) Fuzzy mathematical programming for multi objective linear fractional programming problem. Fuzzy Sets Syst 125(3):335-342

58. Youness E, Emam O, Hafez M (2014) Fuzzy bi-level multi-objective fractional integer programming. Appl Math Inf Sci 8(6): 2857

59. Kauffman A, Gupta MM (1991) Introduction to fuzzy arithmetic: theory and application. Van Nostrand Reinhold, New York 
60. Dubois DJ (1980) Fuzzy sets and systems: theory and applications, vol 144. Academic Press

61. Bellman RE, Zadeh LA (1970) Decision-making in a fuzzy environment. Manag Sci 17(4):B-141-B-164

62. Lai Y-J, Hwang C-L (1994) Fuzzy multiple objective decision making. In: Fuzzy multiple objective decision making. Springer, pp 139-262

63. Jafarian-Moghaddam AR, Ghoseiri K (2012) Multi-objective data envelopment analysis model in fuzzy dynamic environment with missing values. Int J Adv Manuf Technol 61(5-8):771-785
64. Jafarian-Moghaddam AR, Ghoseiri K (2011) Fuzzy dynamic multi-objective data envelopment analysis model. Expert Syst Appl 38(1):850-855

65. Islamic Republic of Iran Railways (2016) Iranian Railways Statistical Yearbook.

66. European Environment Agency (2016) EMEP/EEA air pollutant emission inventory guidebook. 1.A.3.c. Luxembourg 